\title{
SUSTAINABILITY AS A PREDOMINANT FUTURISTIC APPROACH OF THE PRODUCT DESIGN
}

\author{
PROF DR. TAREK ISMAIL MOHAMED
}

Professor of Product Design, College of Mass Communication, Ajman University, United Arab Emirates

\begin{abstract}
This paper presents the value of sustainability as a predominant trend in the future of the product design, Conserving the environment and its capabilities and reducing consumption and waste have all become one of the most important design standards in the modern era, especially with many new design titles such as green design, ecological design, sustainable design.etc.

A lot of design companies and studios in different fields such as product, graphic, interior, architecture, and fashion etc., are still acting within the mentality of profit and loss with no regard for any environmental effects, and then this paper came to discuss the features of the Sustainable products in light of the design process and the development of a new strategy that contributes to relying on sustainable design as a strong partner with the traditional product design for the daily life of the consumers.

\section{Highlights}

- $\quad$ The current design strategy of the products does not care much about the environment and its preservation.

- $\quad$ The product designers must put Sustainability considerations during the design process.

- The new sustainability procedures depend on A new strategy for product design which is called the open system theory.

KEYWORDS: Sustainability, Product Design, Current Design Strategy, Closed System Design Theory, Sustainability Considerations, Open System Design Theory

Funding: This research did not receive any specific grant from funding agencies in the public, commercial, or not-forprofit sectors.
\end{abstract}

Received: Jun 10, 2020; Accepted: Jun 30, 2020; Published: Jul 17, 2020; Paper Id.: IJMPERDJUN2020369

\section{INTRODUCTION}

The term sustainability carries many environmental, social, economic, technological, concepts, etc., and it is related to human health and environment safety and its wealth, and sustainability in the field of product design means the continuity of the product in carrying out its functions without harming the environment, and with the possibility of transforming it from a form to another with changing of its functions in every case to keep its life cycle for the longest possible period, even if it is finished the product components will not become a pollutant in the environment $[1]$.

There is a growing trend in the world towards applying the principles of sustainability in all industrial and economic aspects ... etc., to reduce environmental pollution and the consumption of energy and various materials ... etc., [2] and in the field of product design, the main purpose of sustainability is to eliminate the negative 
environmental impact through the creative design [3].

But the problem of the sustainable products that it may seem as mysterious to the consumers in their external features, materials as well as the used technology of functions and services [4].

Hens, the research seeks to identify the characteristics of those sustainable products, and its design considerations in an attempt to reach a clear strategy that encourage designers to work in this field as well as to go deeper, and remove all the consumers' doubts and fears about those products with spreading a culture of environmental protection and sustainability in the global society.

\section{CURRENT PRODUCT DESIGN STRATEGY}

Product Design is the professional activity of creating and developing concepts with specifications that optimize the function, value, and appearance of objects and services for the mutual benefit of both user and manufacturer [5], the role of the industrial designer is to create solutions for problems of form, appearance, functionality, usability ...etc., [6] for purpose of marketing and sale...etc., the mainline of the design process has changed from product-centered design to usercentered design, this means that the user's desires have the priority in the design process.

In the traditional or current design process which is applied everywhere, we notice that the environmental factor hasn't any priority and it comes as a normal factor of the product design requirements, and there aren't any specific arrangements related to sustainability as shown in figure 1 .

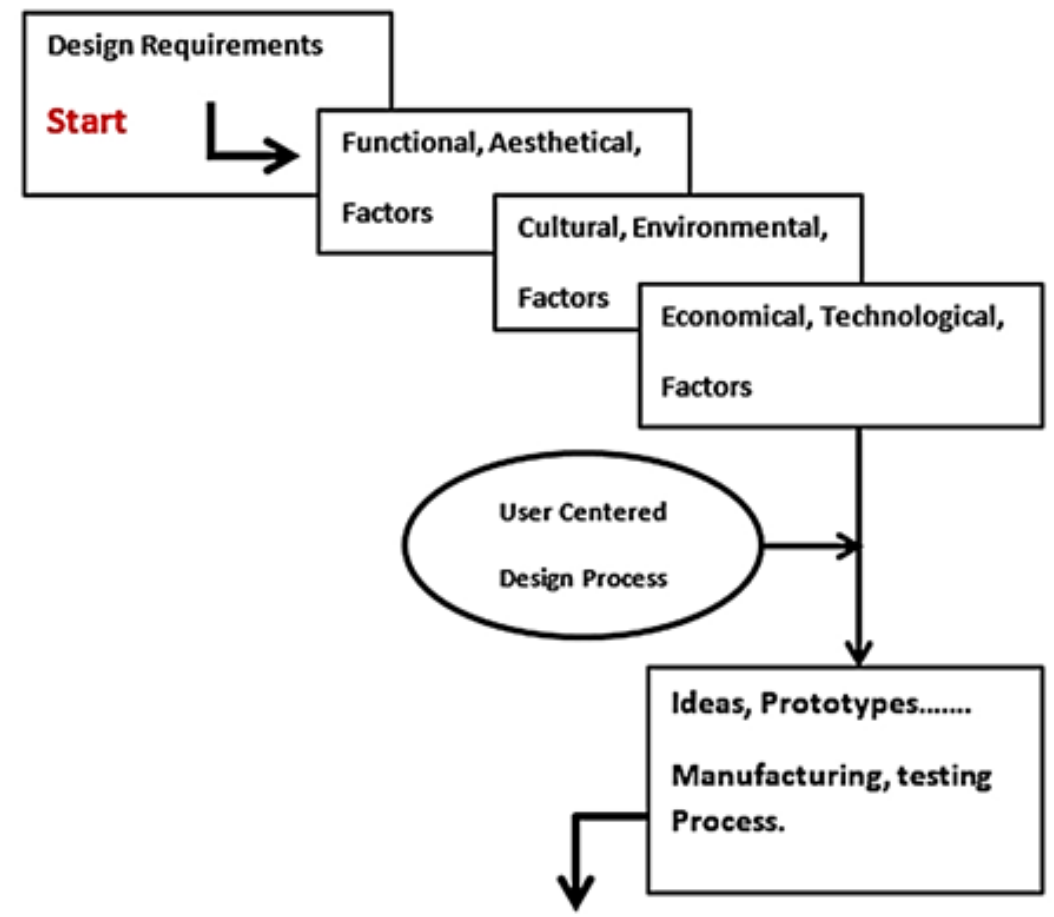

Final Product

Figure 1: Shows the Current Product Design Process.

The manufacturing process of the traditional (none sustainable) products has been organized in a linear flow, it has wastes in many different stages [7], some wastes are formed during the production process as scraps, and some after the product end life, such industrial methods do not apply the requirements of sustainability in protecting the environment 
from pollution and at the same time do not reduce consumption of different materials, as it is noticed that the percentage of losses is large [8], also recycling solutions are small compared to the landfill as shown in figure 2.

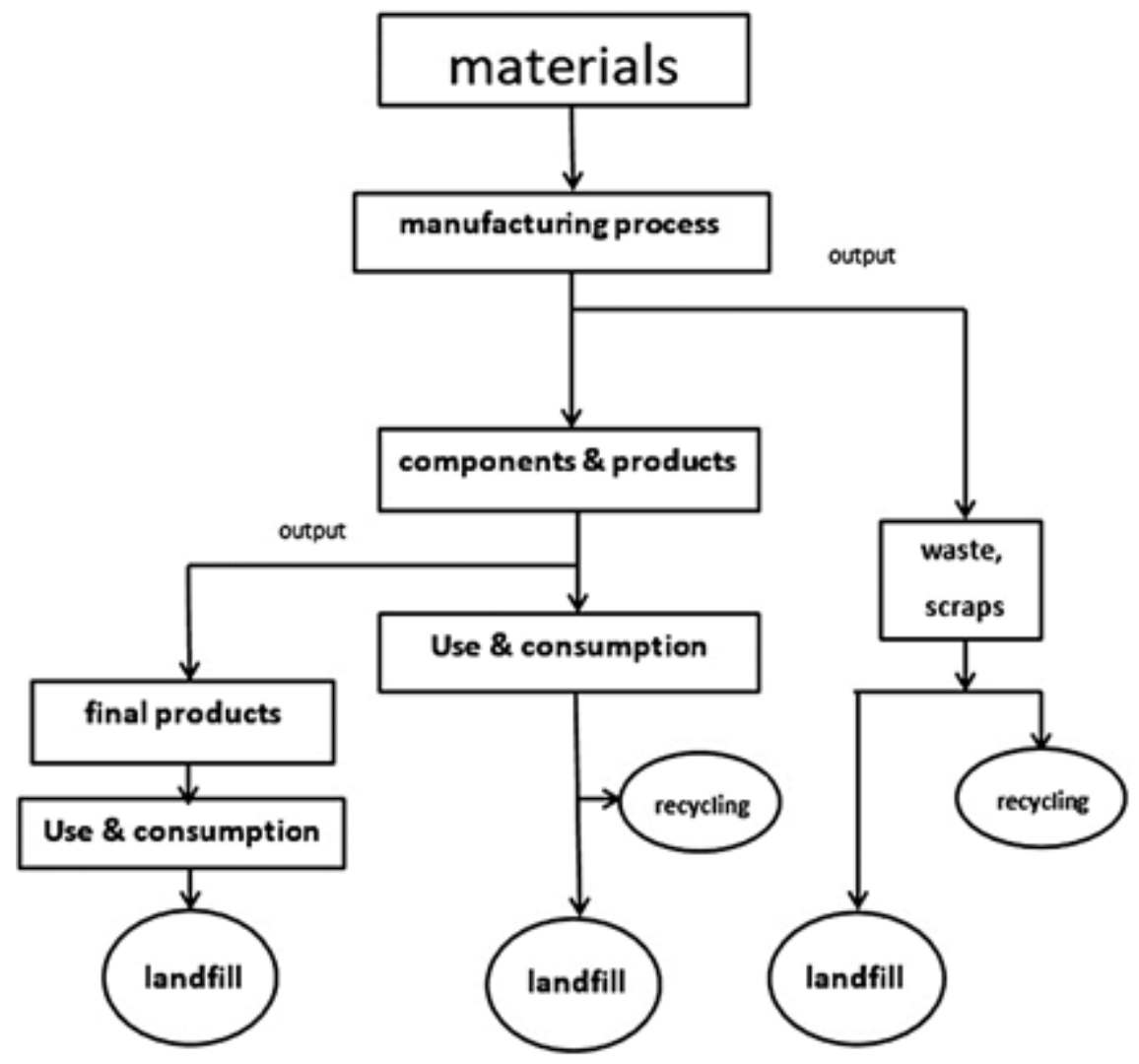

Figure 2: Shows the Linear Manufacturing Process of the None Sustainable Products.

Figure 3 shows different wastes as a result of the none sustainable products after its end of life.
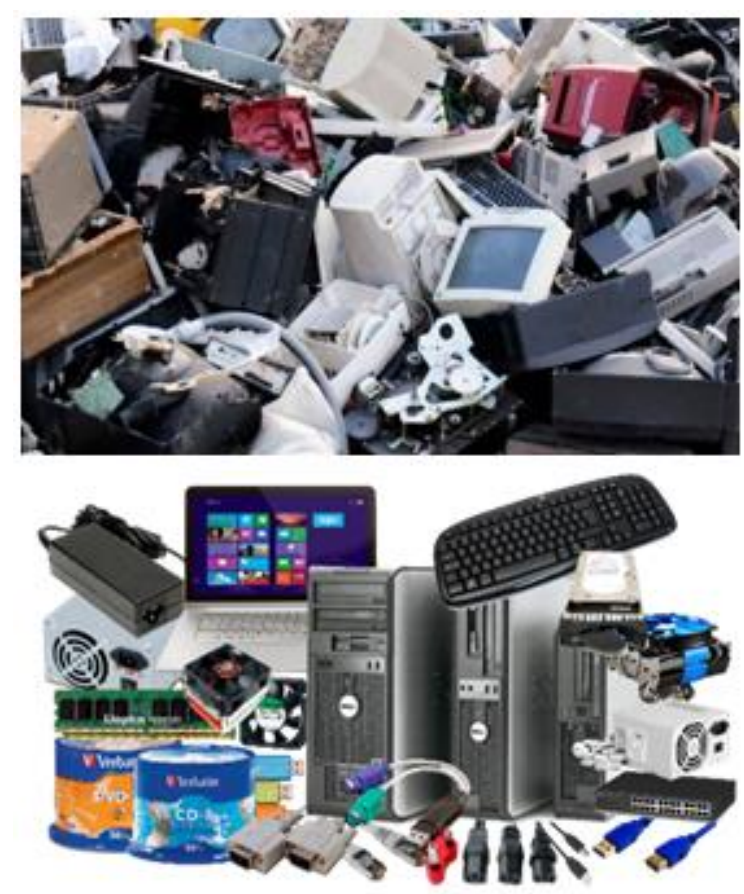

Figure 3: Shows Different Wastes of the None Sustainable Products. 


\section{SUSTAINABLE PRODUCT DESIGN CONSIDERATIONS}

In the topic of design for sustainability, there are some considerations must take place in the designers' mind during the design process and later in manufacturing, these considerations will determine the form features and design specifications of the products as follows: -

\section{Designing for Components and Disassembly}

The goal of designing for components is to identify and optimize the external form of an object, starting with its size and the arrangement of its parts, it can either be easily disassembled or recycled even when it is made of different materials, so it makes sustainability easy [9].

\section{The Lightness of the Material}

Designing according to the logic of reducing materials means optimizing the amount of both materials and energy in the development of a product. Such reduction has a double advantage for sustainability [10], helping to protect the natural sources and decrease harmful emissions, also with using only one material as possible it will simplify both the manufacturing and the final recycling processes, as shown in figure 4.
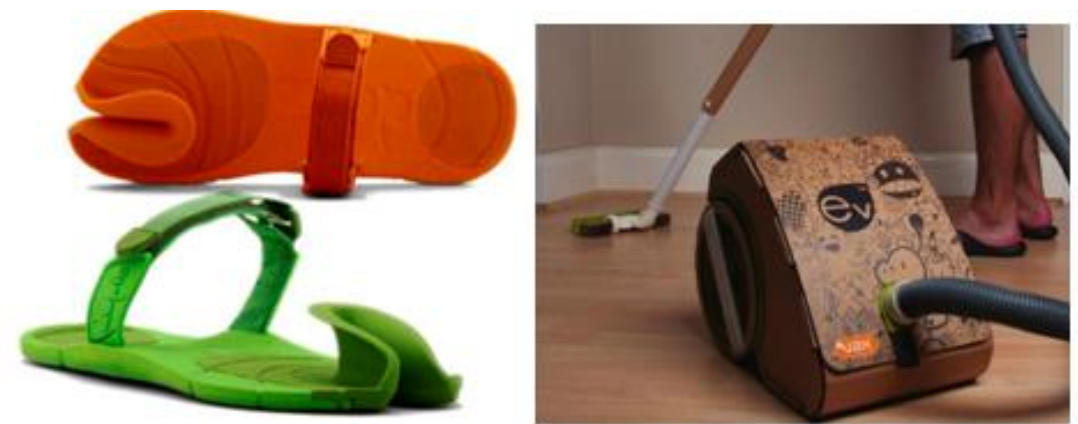

Figure 4: Shows Terra Plana Dopie Sandals and Cardboard Vacuum Cleaner.

\section{Easiness of Re-function the Parts of Used Products}

The process of product disassembly can be followed by a re-function of some parts which are difficult to be recycled, thus achieving a goal of sustainability which must be considered at the beginning of the design process [11], as shown in figure 5 .
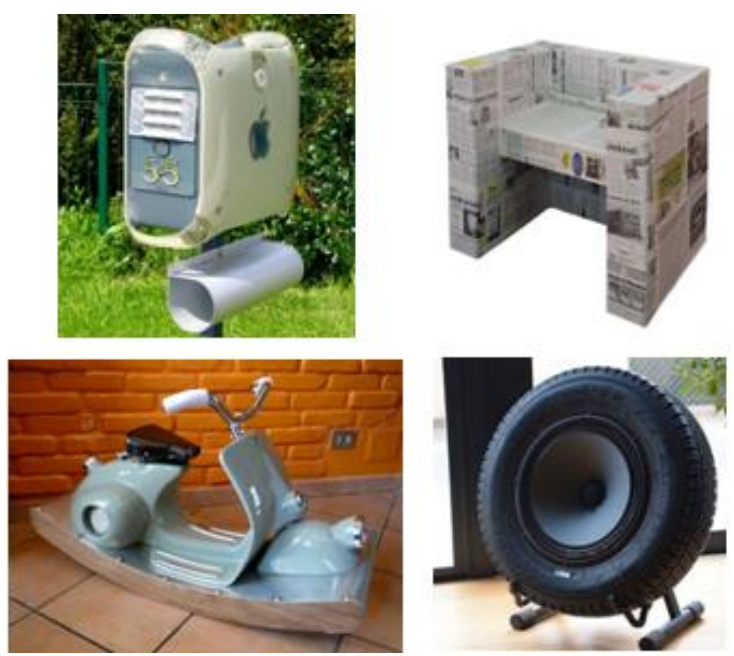

Figure 5: Shows Re-function of the used Product Parts. 


\section{Minimizing the Volume in Product and Packaging}

Decreasing the volume includes the products itself and its packaging, to save materials, transportation energy and emissions, so it is important to apply the minimization principle as we can for both product and packaging at the same time [12], as shown in figure 6 .
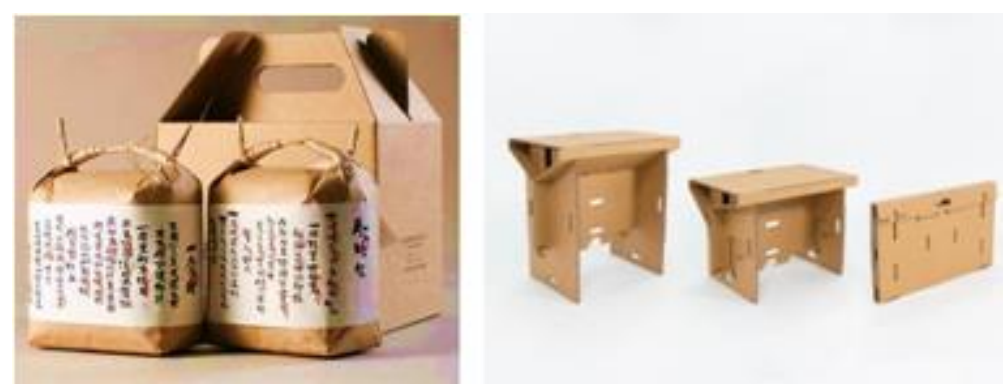

Figure 6: Shows Decreasing the Volume of Product and Packaging.

\section{Designing the Maintenance}

The offer of any purchase now includes the product and its service after sale which must be taken into consideration in the design process, so it is keeping the product life cycle longer and reducing the waste [13].

\section{Using Sustainable Technology}

Sustainable or green technology means using non-conventional, renewable, biological energies, as well as innovative techniques to achieve product functions thus to save energy and realize the zero-emission goal [14], figure 7 shows the eco-car air pod and a biological washing machine without dissolvent.
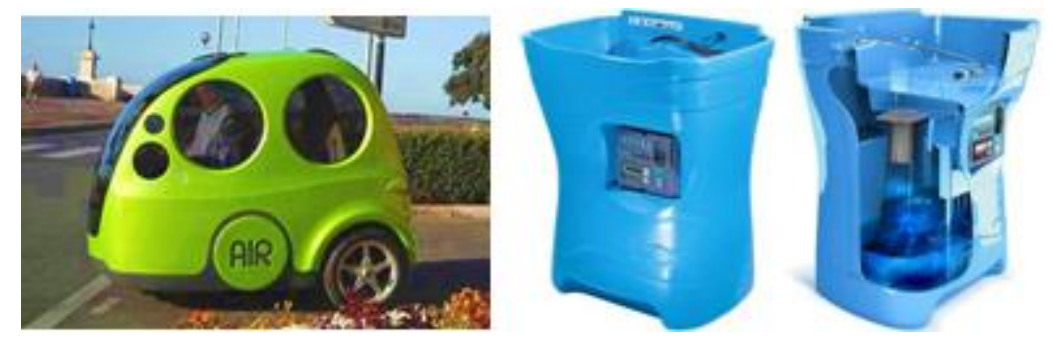

Figure 7: Shows Eco-Car Air Pod and Biological Washing Machine Without Dissolvent.

\section{A NEW STRATEGY FOR SUSTAINABLE PRODUCT DESIGN (THE OPEN SYSTEM DESIGN THEORY)}

An open system is a system that has a relation with the environment as an external interaction, such interaction can take the form of information, energy, or material transfer into or out of the system boundary depending on the discipline which defines the concept, it contrasts with the concept of an isolated or closed system design process which is used in the traditional product design and doesn't exchange any energy, material, information...etc., with its environment [15].

An open system also is known as a constant volume system or a flow system that doesn't end (as a volume or its components) to the landfill.

The different open systems can also interface and interact with each other by receiving inputs and delivering outputs between them, they have permeable boundaries that permit interaction across its boundary through which new information or components are readily absorbed [16]. 
As the environment influences the open system, the open system also influences the environment and allowing ultimately sustaining growth and serving its parent environment, so it has a stronger probability for surviving. Conversely, the closed (isolated) system which resists incorporating new ideas and ceases to properly serve the environment which lives in [17].

The open system theory is based on some principles that serve as guidelines in the design and manufacturing process as follows: -

- During the design and manufacturing process, the outputs of a system as scraps or wastes of material become parts of another system as inputs and create new economic products and new jobs, which are often green jobs [18].

- There is a relationship between every open system and the others, no matter how small it is, the properties of a system arise from the interactions between its components and the other systems' components [19].

- The end of any open system or its parts (the life cycle end), Represent a start for other open systems.

- $\quad$ Self-maintenance leads to zero-emission, such a system is balancing and preserving itself alone.

- With the user-centered system design, the user is a part of the system in which he lives, interacts according to the level of his culture and education.

- Any ecosystem is influenced and shaped by its local environment, so it is important to keep and improve the social and cultural context of its products.

Figure (8) shows the open system design theory, and how the relationship between multi open systems $1,2,3$, ...etc. will keep the sustainability, the outputs of one system or its life cycle end will be the inputs for the other and so on by deconstructing its parts to be recycled or reused in the new natural system or another new open system.

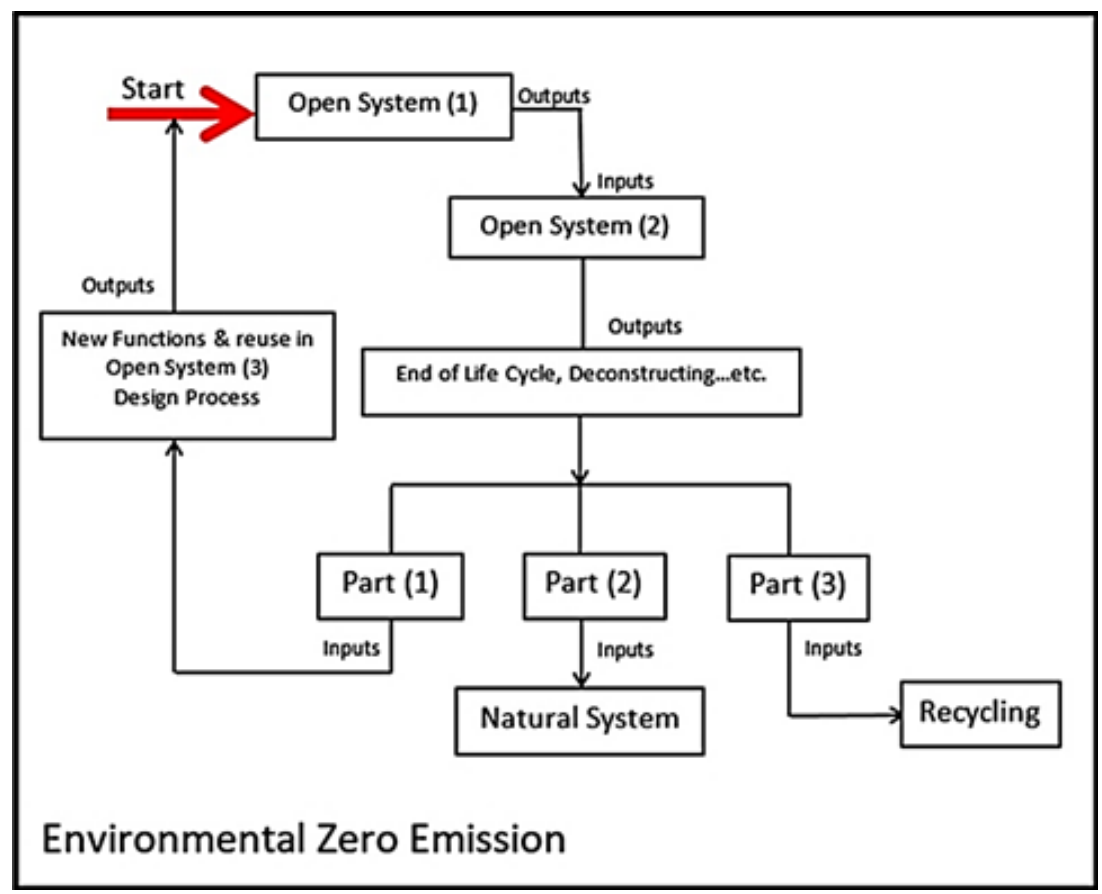

Figure 8: Shows the Open Systems Design Theory. 


\section{MAKING SUSTAINABILITY AS DEFAULT IN PRODUCT DESIGN}

The first challenge of making sustainability as default in design is getting sustainability into the design process, so it becomes a part of the normal way we design [16].

In the virtual experience, sustainability and environmental protection are now visible in the client briefs, policies of different societies, user's habits and designers' thoughts, but it's not true and still facing some problems because sustainability is not the target in the design solution decision, just $14 \%$ of designers say that green issues were an important factor in winning or delivering their works for clients.

Incorporating social and environmental considerations into the design of the future products ensure that we can get zero -emissions, resource efficiency, waste and toxin reduction, so there are some approaches can make sustainability the default design through focusing on: -

\section{Clients and Companies Strategy}

Clients and Companies' Strategy can be bushed towards sustainability through: -

- Legislation and laws of the international community in manufacturing and exporting processes.

- Granting companies that are committed to sustainability application more competitive advantages in markets.

- The client's brief provides the rules to work, so designers' job is to balance these technical, commercial, and customers' parameters, so they can exceed the brief, and embed sustainability to ensure it happens systematically.

- The designers and decision-makers are responsible for reducing the cost of current sustainable products.

\section{Users Sustainable Behavior}

Designers can enable sustainable behavior by understanding the everyday people needs rather than treating them as a problem, sometimes designers may not expect the users' behavior and then they can't control it, so they have to study the social part of people life, such as; what people do, why they do it, how they do it, when they do it, who they do it with, where they do it.

\section{Designers Education}

In order for designers to play their role in moving towards sustainable design, improvements must be taken to the educational process to make sustainability as a strategic goal for designers through different green design practices and many educational subjects that focus on sustainability and its positive sides in peoples' daily life.

\section{CONCLUSIONS}

To achieve transformation towards sustainability in the field of product design, it is important to meet the following aspects: -

- Sustainability must become a part of our everyday thinking.

- Consider the open systems design theory as the default modern design theory in the field of product design.

- Going on different paths to implementing sustainability like clients' and companies' strategy, users' behavior, designers' education, and one path will not enough to achieve the mission. 
- Courses focusing on sustainable development need to place a stronger emphasis on the social context of sustainability.

- The future of product design is in systemic design, thus means the output from one industry becomes the input to another one.

\section{REFERENCES}

1. McLennan. F J. The Philosophy of Sustainable Design. Canada: Ecotone Publishing; 2004.

2. Barbero S. Cozzo B. Eco Design. China: Tandem Verlag; 2009.

3. Ahmad s. Wong YK. Tseng LM. Wong PW. Sustainable product design and development: A review of tools, Applications. J Res Con Rec 2018; 132:49-61.

4. Ceshin F. Gaziulusoy I. Evolution of design for sustainability from product design to design for system innovations and taransitions. J Des Stu 2016; 47: 118-163.

5. Bürdek E B. Design, History, Theory and practice of product design. 1th. Berlin: Birkhaueser; 2005.

6. Quinn D. Design Futures. 2th. London: MERRELL; 2011.

7. Wals. A.E.J. Jickling B. Sustainability in higher education. UK\&USA: Earth scan; 2004.

8. Uffelen V C. Pure Plastic. 1th. Berlin: Verlaghaus Braun; 2008.

9. Berman D. How Designers Can Change the World. San Francisco: Peach pit Press; 2009.

10. Francisco M. Designing with one color and two colors. Spain: Harper design; 2011.

11. Tomkinson B. Tomkinson R. Dobson H. Engel H. Education for sustainable development. UK: Int. J. Sustain; 2008.

12. Quinn B. Design Futures. New York: Merrell; 2011.

13. Slack L. what is product design?. China: Midas Printing International Ltd; 2006.

14. Hazelton J. The big attraction. USA: Screen International; 2013.

15. Hes D. Du Plessis C. Designing for hope. London: Routledge; 2015.

16. Payne A. Will we soon be growing our own vegan leather at home? https://theconversation.com/will-we-soon-be-growing-ourown-vegan-leather-at-home-68498; 2016.

17. Chapman J. To beat the 'throwaway' waste crisis, we must design loveable objects - that last.https://theconversation.com/tobeat-the-throwaway-waste-crisis-we-must-design-loveable-objects-that-last-55269; 2016.

18. Shin D H. Five ways we can harness the original renewable energy source - human power. https://theconversation.com/fiveways-we-can-harness-the-original-renewable-energy-source-human-power-51532; 2015.

19. Wechsler J. The End of Unsustainable Designhttps://medium.com/@jacwex/the-end-of-unsustainable-design-140a6e1516ec 2014.

20. Patil, Jayashree Sandeep, and A. P. Sarode. "Contribution of Employees: Engagement and Participation of Employees in Green HRM to Achieve Sustainability." International Journal of Human Resources Management (IJHRM) 8.6 (2019):13-18.

21. Hsiao, M. K. "Current sustainability marketing and communications effect to consumer's attitude to purchase sustainable products." International Journal of Research in Business Management (IJRBM) 1.2 (2013): 45-54. 
22. Pallavi, Evpas, and MVV Bhanu. "Green HRM: A Way for Corporate Sustainability." International Journal of Human Resource Management and Research (IJHRMR) 6.2 (2016): 13-20.

23. Egbeleke, Adeyemi Ademola. "From Carroll's Pyramid to Elkington TBL: A Move towards Integrated Impact Assessment Driven Corporate Responsibility and Sustainability Performance Reporting System." International Journal of Business Management \& Research (IJBMR) 3.4 (2013): 93-104.

24. Chikwe, John E., and Chris Sam Biriowu. "Strategic Planning and Firm's Sustainability in Turbulent Business Operating Environment: Lessons from Selected Oil and Gas Industry in Nigeria." International Journal of Business and General Management (IJBGM) 7.6 (2018): 5-16. 

